\title{
GENETIC INACTIVATION OF PLEIOTROPHIN TRIGGERS AMPHETAMINE-INDUCED CELL LOSS IN THE SUBSTANTIA NIGRA AND ENHANCES AMPHETAMINE NEUROTOXICITY IN THE STRIATUM
}

Esther Gramage ${ }^{a}$, Luca Rossi ${ }^{a}$, Noelia Granado ${ }^{\text {b,c }}$, Rosario Moratalla ${ }^{\text {b,c }}$ and Gonzalo Herradón $^{\text {a }}$

${ }^{a}$ Lab. Pharmacology and Toxicology, Univ. San Pablo CEU, 28668 Boadilla del Monte, Madrid, Spain.

b Instituto Cajal, Consejo Superior de Investigaciones Científicas, CSIC, 28002 Madrid, Spain.

${ }^{c}$ CIBERNED, Instituto de Salud Carlos III, Madrid, Spain

*Corresponding author

Gonzalo Herradon, $\mathrm{PhD}$

Lab. Pharmacology and Toxicology

Universidad San Pablo CEU

Urb. Montepríncipe

28668 Boadilla del Monte, Madrid, Spain.

Tel: 34-91-3724700 (Ext. 4840)

Fax: 34-91-3510475

e-mail: herradon@ceu.es 


\section{ABSTRACT}

Pleiotrophin (PTN) is a neurotrophic factor with important effects in survival and differentiation of dopaminergic neurons that has been suggested to play important roles in drug of abuse-induced neurotoxicity. To test this hypothesis, we have studied the effects of amphetamine $(10 \mathrm{mg} / \mathrm{kg}, 4$ times, every $2 \mathrm{~h})$ on the nigrostriatal pathway of PTN genetically deficient (PTN-/-) mice. We found that amphetamine causes a significantly enhanced loss of dopaminergic terminals in the striatum of PTN-/- mice compared to wild type $(\mathrm{WT}+/+)$ mice. In addition, we found a significant decrease $(\sim 20 \%)$ of tyrosine hydroxylase (TH)-positive neurons only in the substantia nigra of amphetamine-treated PTN-/- mice, whereas this area of $\mathrm{WT}+/+$ animals remained unaffected after amphetamine treatment. This effect was accompanied by enhanced amphetamine-induced astrocytosis in the substantia nigra of PTN-/- mice. Interestingly, we found a significant decrease in the phosphorylation levels of p42 ExtracellularSignal Regulated Kinase (ERK2) in both saline- and amphetamine-treated PTN-/- mice, whereas phosphorylation of p44 ERK (ERK1) was almost abolished in the striatum of PTN-/- mice compared to WT+/+ mice, suggesting that basal deficiencies in the phosphorylation levels of ERK1/2 could underlie the higher vulnerability of PTN-/mice to amphetamine-induced neurotoxic effects. The data suggest an important role of PTN in the protection of nigrostriatal pathways against amphetamine insult.

Keywords: Neurotoxicity, methamphetamine, MDMA, RPTP $\beta / \zeta$, ERK1/2, Fyn. 
Amphetamine and its derivatives are drugs of abuse with high addictive potential that induce severe neurotoxic effects within the central nervous system (Yamamoto and Bankson 2005), such as proliferation of astrocytes in striatum ( $\mathrm{Pu}$ and Vorhees 1995; Krasnova et al., 2005), apoptosis of striatal neurons and destruction of striatal dopaminergic terminals (Krasnova et al., 2005). The amphetamine derivative 3,4methylenedioxymethamphetamine (MDMA, ecstasy) reduces striatal dopamine (DA) content, tyrosine hydroxylase (TH), and DA transporter-immunoreactivity in mice to a higher extent than amphetamine (Granado et al., 2008a, b). It has been shown that methamphetamine treatment causes significant decreases in the number of tyrosine hydroxylase-positive cells in the substantia nigra pars compacta (Sonsalla et al., 1996; Hirata and Cadet, 1997). Furthermore, we have recently shown that MDMA and methamphetamine reduce $\mathrm{TH}$ fibers in the striatum and that this reduction is larger in the striosomes than in the matrix (Granado et al., 2008a, 2010) although the nucleus accumbens was not affected by either drug. In addition, we demonstrated that MDMA produces a significant decrease in the number of $\mathrm{TH}$-immunoreactive neurons in the mouse substantia nigra along with an increase in Fluoro Jade staining (Granado et al., 2008b), an effect that is not found in amphetamine-treated mice. TH+ cell loss in the SN was accompanied by an increase in astrogliosis observed 3 days after MDMA treatment (Granado et al., 2008b).

Although the neurotoxic effects of this type of drugs have been associated with an increase in reactive oxygen species, cytokines and DNA damage, the mechanisms of neuronal degeneration are not well understood and several factors may play critical roles. For instance, the expression levels of the cytokine Pleiotrophin (PTN) (Li et al. 1990), known for its well-documented neurotrophic actions on dopaminergic neurons (Hida et al., 2003; Jung et al., 2004; Hida et al., 2007; Herradon and Ezquerra 2009) are 
significantly upregulated in the nucleus accumbens after amphetamine administration (Le Greves 2005). Interestingly, as mentioned above, the nucleus accumbens seems to be protected against amphetamine-derivatives-induced neurotoxicity compared to other areas such as substantia nigra and striatum (Granado et al, 2008b and 2010), suggesting a role of PTN on amphetamine-induced neurotoxicity. Pleiotrophin is a secreted growth factor (Milner et al. 1989; Rauvala 1989; Li et al. 1990) with important roles in neuronal differentiation during development (see review by Herradon et al. 2009). In adults, PTN expression is highly restricted to specific sites of the brain such as dopaminergic neurons of the substantia nigra (Marchionini et al. 2007) and striatal interneurons (Taravini et al. 2005). Interestingly, PTN has been found to regulate the levels of expression of $\mathrm{TH}$, the rate limiting enzyme of the catecholamine biosynthesis (Jung et al. 2004). More importantly, PTN promotes survival of dopaminergic neurons in vitro (Hida et al. 2003) and regulates the production of dopaminergic neurons from embryonic stem cell-derived nestin-positive cells (Jung et al. 2004). These findings strongly suggest the possibility that PTN is being upregulated after amphetamine administration (Le Greves, 2005) as an adaptative response to counteract amphetamineinduced neurotoxic effects. This suggestion is supported by the ability of PTN to exert trophic effects on donor cells in neural transplantation in vivo to achieve functional recovery of nigrostriatal pathways (Hida et al. 2007). In addition, we have recently shown enhanced amphetamine-induced astrocytosis in the striatum of PTN genetically deficient (PTN-/-) mice (Gramage et al., 2010). We have also shown that exogenous PTN efficiently protects PC12 cell cultures from cocaine insult (Gramage et al., 2008) and from amphetamine-induced cytotoxicity through the ability of PTN to increase the phosphorylation levels of Extracellular-Signal Regulated Kinase 1/2 (ERK1/2) 
(Gramage et al., 2010). Whether or not this mechanism is involved in PTN neuroprotective effects in vivo remained to be elucidated.

Since PTN seems to be an important factor with trophic effects on dopaminergic neurons and its levels of expression are significantly regulated by amphetamine administration, we have now aimed to characterize amphetamine-induced toxicity in the nigrostriatal pathway of PTN-/- mice compared to wild type (WT+/+) mice in an effort to better understand the role of PTN on amphetamine-induced neurotoxic effects in vivo. 


\section{EXPERIMENTAL PROCEDURES}

\section{Pleiotrophin genetically deficient (PTN-/-) mice}

Pleiotrophin knockout (PTN-/-) mice were kindly provided by Dr. Thomas F. Deuel (The Scripps Research Institute, La Jolla, CA). PTN-/- mice were generated as previously described (Amet et al. 2001; Del Olmo et al., 2009). The PTN gene consists of five exons encoding an $18-\mathrm{kDa}$ protein with a 32 amino acid signal peptide. The replacement targeting vector generated a PTN null allele $\left(\mathrm{PTN}^{2-4 n e o}\right)$ by deleting exons 2 to 4 . In our studies using amphetamine- and saline-treated mice, we used male PTN-/and wild type (WT, +/+) animals of 9-10 weeks (20-25 g).

All the animals used in this study were maintained in accordance with European Union Laboratory Animal Care Rules (86/609/ECC directive) and the protocols were approved by the Animal Research Committee of USP-CEU.

\section{Body temperature}

PTN-/- and WT+/+ mice received 4 injections (i.p.) of amphetamine (Sigma, Madrid, Spain) (10 mg/kg) or saline (control, $10 \mathrm{ml} / \mathrm{Kg}$ ), allowing between injections a 2 hour interval. This regimen of amphetamine administrations is widely used to study amphetamine-induced neurotoxic effects and has significantly contributed to describe the well documented astrocytosis and loss of dopaminergic terminals in the striatum induced by amphetamine (Krasnova et al., 2001, 2002 and 2005; Atianjoh et al., 2008). Krasnova et al. (2005), using this same regimen, reported that amphetamine-induced astrocytosis in the striatum peaks 4 days after amphetamine administrations, being this effect reversible 7 days after drug administrations. In that report, it was also confirmed that amphetamine does not affect dopaminergic neurons of the substantia nigra, thus 
suggesting moderate neurotoxic consequences after using this drug regimen. Rectal temperature was determined in basal conditions and 30 min after each administration in lightly restrained mice ( $\mathrm{n}=7-8$ /group) with a digital thermistoprobe.

\section{Tyrosine Hydroxylase (TH) and Glial-Fibrillary Acidic Protein (GFAP)}

\section{immunohistochemistry studies}

Four days after the animals received the first administration of amphetamine or saline, mice ( $n=5 /$ group) were euthanized and brains rapidly removed and conserved in p-formaldehyde for 7 days.

\section{Immunohistochemistry}

Coronal brain sections $(30 \mu \mathrm{m})$ were obtained on a slicing vibratome (Leica, Madrid, Spain) and kept in PB solution at $4^{\circ} \mathrm{C}$ until use. Immunostaining was carried out on free-floating sections with a standard avidin-biotin immunocytochemical protocol previously described (Pavon et al. 2006, Rodrigues et al. 2007, Darmopil et al., 2008, 2009). Sections were incubated overnight with the following specific primary antisera (Ab-I): rabbit tyrosine hydroxylase $(\mathrm{TH})$ antiserum (Chemicon International, Temecula, CA, USA) diluted 1:1,000, and a rabbit anti glial fibrillary acidic protein (GFAP) antibody (DakoCytomation, Denmark) diluted 1:1,000 in PBST solutions containing normal goat serum. After careful washing, the sections for $\mathrm{TH}$ analysis were incubated with the biotinylated secondary antisera (Vector, Burlingame, CA) at room temperature and developed using diaminobenzidine (DAB). The sections for GFAP analysis were incubated with Alexa Fluor 488 goat anti-rabbit IgG.

Quantification of expression of TH in striatum sections was performed with the aid of an image analysis system (Analytical Imaging Station (AIS), Imaging Research Inc., Linton, UK) using a 5x lens, converting colour intensities into a gray scale and 
quantifying the stained striatal area as a proportion of the total striatal area. For each section, the contour of the striatum was outlined with the aid of the AIS system to get the total striatal area. The data is expressed as proportional stained area (Granado et al. 2008a, b; Martin et al. 2008). A total of 5-6 rostrocaudal sections were used per animal. In a similar manner, we quantified GFAP stained area from each section of the substantia nigra using methods similar to those described by others (Sabri et al., 2008). All images were viewed under a microscope at the same light intensity and were captured. To eliminate background noise, a single threshold was applied to all images based on selection of what appeared as intracellular specific GFAP staining and areas of higher intensity then were taken as being GFAP-positive.

\section{Stereological quantification of TH positive neurons in $S N p c$}

The total number of TH-positive SNpc neurons was counted in the different amphetamine- or saline- treated animals using the optical fractionator (Granado et al., 2008b). The researcher doing the stereological counting was blind to the experimental condition of the animal being counted. This unbiased method of cell counting is not affected by either the volume of reference $(\mathrm{SNpc})$ or the size of the counted element (neurons). TH-positive neurons were counted in the left SNpc of every fourth section (9-12 sections per animal) throughout the entire extent of the SNpc (Jackson-Lewis et al. 2000). Each midbrain section was viewed at low power (4x objective) and the SNpc was outlined by using the set of anatomic landmarks defined previously (Jackson-Lewis et al. 2000). Then, starting at a random microscope visual field, the number of THstained cells was counted (20x). To avoid double counting of neurons with unusual shapes, TH-stained cells were counted only when their nuclei were optimally visualized which occurred only in one focal plane. 


\section{Western blots}

\section{Dopamine Transporter (DAT).}

After sacrifice, the striatum from saline- and amphetamine-treated PTN-/- and $\mathrm{WT}+/+$ mice $(\mathrm{n}=5-6 /$ group$)$ different from those used in immunohistochemistry studies were rapidly dissected, frozen in dry ice and stored to $-80^{\circ} \mathrm{C}$ until the protein extraction procedure. Tissue samples were homogenized in RIPA buffer and protein extracted in presence of protease inhibitors. Total protein was quantified by the Bradford protein assay (Pierce, Rockford, IL). Equilibrated protein samples were mixed with loading buffer $(60 \mathrm{mM}$ Tris $\mathrm{pH} 6.8,10 \%$ glycerol, $5 \%$ SDS, $0.65 \% \quad \beta$ mercaptoethanol, and $0.01 \%$ bromophenol blue), boiled for 5 minutes, and loaded onto $10 \%$ polyacrylamide gels as appropriate. The gels were transferred to nitrocellulose membranes that were blocked with $50 \mathrm{mM}$ Tris, $150 \mathrm{mM} \mathrm{NaCl}, 0.1 \%$ Tween-20 (TBS-T) and 5\% non-fat milk for 1 hour, probed with anti-DAT antibodies (Chemicon, Temecula, CA) at a 1:1,000 dilution, and re-probed with anti-actin antibodies at a 1:2,000 dilution (Chemicon, Temecula, CA). Signal was detected with horseradish peroxidase (HRP) conjugated secondary antibodies diluted 1:5,000 (Santa Cruz, Santa Cruz, CA), and the immunoreactive proteins visualized using the ECL enhanced method (Amersham, San Francisco, CA). We quantified DAT protein levels by densitometry in each animal sample using quantity one software (Bio-Rad, Hercules, CA). Actin protein levels were measured by densitometry to normalize DAT levels of expression.

\section{Phospho-ERK1/2 and ERK1/2.}

Protein from tissue samples from saline- and amphetamine-treated PTN-/- and $\mathrm{WT}+/+$ mice $(\mathrm{n}=4-6 /$ experimental group) was extracted as above but, in this case, in presence of a phosphatase inhibitor cocktail (Sigma, Madrid, Spain). Total protein was 
quantified as above and equilibrated protein samples mixed with loading buffer were loaded onto $12 \%$ polyacrylamide gels. The gels were transferred to nitrocellulose membranes that were blocked as above, and then probed with anti-phospho-ERK1/2 $(1: 1,000)$ antibodies (Cell signaling, Danvers, MA) and reprobed with anti-ERK1/2 $(1: 2,000)$ antibodies (Cell signaling, Danvers, MA) to confirm the identity of the protein. After 3 washes in TBS-T, the membranes were incubated for one hour with appropriate secondary antibodies conjugated with horseradish peroxidase diluted 1:5,000 in TBS-T with 5\% non-fat milk for $30 \mathrm{~min}$. The membranes were washed 3 times in TBS-T and the immunoreactive proteins were visualized using the ECL Enhanced method according to the manufacturer's instructions. We quantified phosphoERK1 and phospho-ERK2 protein levels by densitometry in each animal sample as above. Total ERK1 and ERK2 protein levels were measured by densitometry to normalize phospho-ERK1 and phospho-ERK2 levels.

\section{Statistics}

Data are presented as mean \pm standard error of the mean (S.E.M.). The results of rectal temperature measurements were analysed using two-way analysis of variance (ANOVA) for repeated measures. Data obtained from image analysis of striatal and nigral immunostaining, stereology and Western Blots were analysed using two-way ANOVA. Relevant differences were analyzed pair-wise by post-hoc comparisons with Bonferroni's post-hoc tests, considering genotype (PTN-/-, WT+/+) and treatment (saline, amphetamine) as variables. $\mathrm{P}<0.05$ was considered as statistically significant. All statistical analyses were performed using graphpad prism 4 program. 


\section{RESULTS}

In the experiments presented here, $\mathrm{PTN}-/-$ and $\mathrm{WT}+/+$ mice received $10 \mathrm{mg} / \mathrm{kg}$ amphetamine i.p. four times in 2-hour intervals. Although amphetamine is known to produce more severe hyperthermic effects in rats, we measured mouse body temperature 30 minutes after each administration of amphetamine as a control to discard the possibility that any damage we could find in these mice could be due to amphetamineinduced hyperthermia. We did not detect differences in the basal temperatures of PTN-/and $\mathrm{WT}+/+$ mice (table 1 ). Both PTN-/- and $\mathrm{WT}+/+$ mice showed a similar increase in body temperature after the first administration of amphetamine reaching a temperature peak of $37.7^{\circ} \mathrm{C}$ and $37.8^{\circ} \mathrm{C}$ respectively (table 1). Statistical differences between amphetamine-treated PTN-/- and WT+/+ mice were only achieved after the second amphetamine administration $\left(37.8^{\circ} \mathrm{C}\right.$ vs. $\left.36.8^{\circ} \mathrm{C}\right)$. The data confirm that amphetamine administration causes modest hyperthermic effects in both mice genotypes used in our studies.

Enhanced amphetamine-induced loss of tyrosine hydroxylase in the striatum of Pleiotrophin knockout mice.

Since one of the consequences of amphetamine administration is the loss of dopaminergic terminals in the striatum (Bowyer et al., 1998), we analyzed by immunohistochemistry the TH expression and by Western blots DAT expression in the striatum of PTN-/- and WT+/+ mice treated with either amphetamine or saline (control). ANOVA revealed a significant effect of the genotype $(\mathrm{F}(1,16)=4.725 ; \mathrm{P}<0.05)$ and a significant effect of the treatment $(\mathrm{F}(1,16)=59.68 ; \mathrm{P}<0.0001)$. Amphetamine caused a $\sim 50 \%$ depletion of $\mathrm{TH}$ contents in the striatum of $\mathrm{WT}+/+$ mice compared with saline- 
treated WT+/+ mice (Fig. 1). Interestingly, we detected a significantly greater decrease of $\mathrm{TH}$ levels in the striatum of PTN-/- mice treated with amphetamine compared to WT+/+ mice (Fig. 1). However, we did not detect significant differences in the levels of TH in the striatum of saline-treated PTN-/- and WT+/+ mice (Fig. 1). These data were paralleled by a greater depletion of DAT levels in amphetamine-treated PTN-/- mice as assessed in Western blots (Fig. 2). The data confirm that amphetamine produces degeneration of dopaminergic terminals in the striatum. Furthermore, these data suggest that endogenous PTN is not a key factor for TH expression in the mouse striatum in normal condition but is a factor that critically modulates the severity of amphetamineinduced neurotoxicity in the dopaminergic terminals of the striatum.

Amphetamine induces loss of TH+ neurons only in the substantia nigra of Pleiotrophin knockout mice.

It was previously found that the amphetamine derivatives MDMA and methamphetamine cause significant decreases in the number of $\mathrm{TH}+$ cells in the substantia nigra (Sonsalla et al., 1996; Hirata and Cadet, 1997; Granado et al., 2008b). In contrast, amphetamine is known to induce degeneration of dopaminergic terminals in striatum with no effect on the neuronal bodies located in the substantia nigra (Krasnova et al., 2005). To test the possibility that endogenous PTN may be acting as a defense mechanism against amphetamine-induced neurotoxicity in the substantia nigra, we assessed the number of $\mathrm{TH}+$ cells in the substantia nigra of saline- and amphetaminetreated PTN-/- and WT+/+ mice, uncovering significant differences between genotypes $(\mathrm{F}(1,15)=5.219 ; \mathrm{P}<0.05)$. We found similar numbers of $\mathrm{TH}+$ cells in saline-treated PTN-/- and WT+/+ mice (Fig. 3). We also found that amphetamine did not cause any change in the number of $\mathrm{TH}+$ cells of $\mathrm{WT}+/+$ mice treated with amphetamine compared 
with saline-treated animals (Fig. 3). In contrast, we found a significant decrease in the number of $\mathrm{TH}+$ cells in the substantia nigra of PTN-/- mice treated with amphetamine compared to saline-treated mice (Fig. 3). To the best of our knowledge, this is the first evidence showing amphetamine-induced loss of TH+ cells in mice.

As an indirect marker of neuronal damage in the substantia nigra, we tested as well GFAP+ cells in this brain area of saline- and amphetamine-treated PTN-/- and $\mathrm{WT}+/+$ mice. Amphetamine increased GFAP immunostaining in both genotypes compared with saline-treated groups, although this effect was only found to be statistically significant in the case of PTN-/- mice (Fig. 4).

\section{Decreased phosphorylation levels of ERK1/2 in the striatum of Pleiotrophin knockout mice.}

Recently, we showed that PTN protects PC12 cell cultures against amphetamineinduced toxicity through the ability of PTN to increase the phosphorylation levels of ERK1/2 in these cells (Gramage et al., 2010). To test the possibility that differences in the phosphorylation levels of ERK1/2 in PTN-/- and WT+/+ mice could underlie the different vulnerability of these mouse genotypes to the neurotoxic effects induced by amphetamine, we studied the levels of phospho-ERK1/2 in striatum of saline- and amphetamine-treated PTN-/- and WT+/+ mice. ANOVA revealed a significant effect of the genotype in both p44 ERK (ERK1) and p42 ERK (ERK2) $(\mathrm{p} 44, \mathrm{~F}(1,16)=9.17, \mathrm{P}=$ $0.008 ; \mathrm{p} 42, \mathrm{~F}(1,16)=17.30, \mathrm{P}=0.0007)$. We did not find significant differences in the phosphorylation levels of p42 ERK in amphetamine-treated mice compared to salinetreated mice of either genotype (Fig. 5). Interestingly, the phosphorylation levels of p42 ERK were found to be decreased in the striatum of PTN-/- mice either treated with saline or amphetamine. Similar results were obtained with p44 ERK, although in this 
case differences between genotypes were even more pronounced since the phosphorylation form of p44 ERK was almost lacking in PTN-/- mice (Fig. 5), whereas regular amounts of total ERK1/2 proteins were found in both mouse genotypes and they were not influenced by the treatment (Fig. 5). 


\section{DISCUSSION}

We have recently shown that $\mathrm{WT}+/+$ mice extinguish amphetamine-seeking behaviour before than PTN-/- mice (Gramage et al., 2010), uncovering a higher vulnerability of mice lacking endogenous PTN to the pharmacological effects of amphetamine. In that report, it was also shown that amphetamine-induced astrocytosis in the striatum is significantly enhanced in PTN-/- mice, suggesting that endogenous PTN could play an important role in amphetamine-induced neurotoxic effects. Those data led us to perform a series of studies designed to better understand the consequences of amphetamine administration in the nigrostriatal pathway in absence of endogenous PTN. Here, we show that the previously reported amphetamine-induced astrocytosis in the striatum of PTN-/- mice is accompanied by a greater loss of dopaminergic terminals in PTN-/- mice compared to WT+/+ mice. These neurotoxic effects of amphetamine within the striatum had been shown before in normal mice (Yamamoto and Bankson, 2005). However, we now demonstrate that endogenous PTN is key to limit amphetamine-induced loss of dopaminergic terminals in the striatum. Surprisingly, when we studied amphetamine effects in the substantia nigra, a brain area mostly occupied by dopaminergic neurons projecting to the striatum, we found enhanced amphetamine-induced astrocytosis in PTN-/- mice and, more importantly, a significant loss of TH+ cells only in PTN-/- mice. To the best of our knowledge, this is the first evidence showing that amphetamine reduces the number of $\mathrm{TH}+$ neurons in the substantia nigra in vivo, since normal mice do not suffer this amphetamine effect as we have confirmed in our WT+/+ (control) mice. Thus, the data identify for the first time PTN as a single genetic factor that critically modulates previously unknown amphetamine neurotoxic effects. Furthermore, the data suggest that mutations in the 
PTN gene leading to a loss of its function could underlie increased vulnerability to amphetamine-induced neurotoxic effects in humans.

Pleiotrophin is a cytokine with known effects on survival and differentiation of neurons in different contexts (see review by Herradon et al. 2009). It has been previously demonstrated that PTN is a key factor for survival of the injured dopaminergic neurons in vitro and in vivo (Hida et al. 2003; Jung et al. 2004; Hida et al. 2007), results that became promising when PTN was found to be significantly upregulated in the substantia nigra of patients with Parkinson's disease (Marchionini et al., 2007). The present data suggest that PTN could play important roles in another dopaminergic-related pathology such as drug addiction, since dopaminergic neurons are the main target for different drugs of abuse such as amphetamine and its derivatives. Furthermore, our data contribute to the significance of a previous report showing that PTN is significantly upregulated in the nucleus accumbens in response to amphetamine (Le Greves 2005), leading us to suggest that upregulation of endogenous PTN levels may be counteracting amphetamine-induced neurotoxic effects as it may be happening as well in Parkinson's disease (Marchionini et al., 2007).

We previously found that exogenous PTN protects the catecholaminergic PC12 cell line from amphetamine-induced toxicity through the ability of PTN to increase the phosphorylation levels of ERK1/2 (Gramage et al., 2010). In the present work, we have tested the possibility that lack of endogenous PTN could lead to decreased phosphorylation of ERK1/2 in PTN-/- mice, as a potential mechanism to explain the increased vulnerability of PTN-/- mice to amphetamine-induced neurotoxic effects. We found that the levels of phosphorylation of ERK1/2 are strikingly decreased in striatum of PTN-/- mice either treated with saline or amphetamine. The case of p44 ERK (ERK1) is especially remarkable since its phosphorylation form is nearly undetectable 
in the striatum of PTN-/- mice, suggesting a possible specific role of this isoform in the modulation of amphetamine-induced neurotoxicity in this brain area. In any case, the data suggest that deficiencies in the control of phosphorylation of ERK1/2 in PTN-/mice could underlie the enhanced amphetamine-induced loss of dopaminergic terminals and astrocytosis in the striatum compared to normal WT+/+ mice. This is supported by previous evidence showing that serotonin depletions induced by the amphetamine derivative MDMA are attenuated by increased phosphorylation of ERK1/2 in the rat striatum (Goñi-Allo et al., 2008). In addition, increased phosphorylation, and thus, activation, of ERK1/2 protects the brain from damage in different contexts such as ischemic stroke (Jia et al., 2008).

It is interesting to note that PTN-induced phosphorylation of ERK1/2 in PC12 cells (Gramage et al., 2010) and decreased phosphorylation levels of ERK1/2 in the striatum of PTN-/- mice could be linked with the known mechanism of action of PTN. One receptor that initiates PTN signaling is the trans-membrane receptor protein tyrosine phosphatase (RPTP) $\beta / \zeta$ (Meng et al., 2000). The interaction of PTN with $\mathrm{RPTP} \beta / \zeta$ induces receptor dimerization and inactivates the endogenous tyrosine phosphatase activity of RPTP $\beta / \zeta$, thereby disrupting the balanced activity of RPTP $\beta / \zeta$ and an unknown but constitutively active tyrosine kinase(s) on the mutual substrates of $\mathrm{RPTP} \beta / \zeta$ and the tyrosine kinase and thus initiating a sharp and rapid increase in the steady state levels of tyrosine phosphorylation (Meng et al., 2000; Fukada et al., 2006). One of the substrates of RPTP $\beta / \zeta$ whose levels of tyrosine phosphorylation are increased by PTN is Fyn kinase (Pariser et al., 2005). Fyn has been shown to activate ERK1/2 signaling pathway by increasing the phosphorylation levels of ERK1/2 (Lovatt et al., 2006), suggesting Fyn could serve the PTN/RPTP $\beta / \zeta$ signaling pathway to phosphorylate ERK1/2 and, through this mechanism, protect against amphetamine- 
induced toxicity in vivo and in vitro. Whether or not other known substrates of RPTP $\beta / \zeta$ are involved in PTN neuroprotective effects remains to be studied and their possible roles against drug of abuse-induced toxicity have been recently reviewed (Herradon et al., 2009).

In summary, in this work we demonstrate for the first time that lack of endogenous PTN critically modulates amphetamine-induced neurotoxic effects, including previously unexpected toxic effects of amphetamine within the dopaminergic neurons in the substantia nigra.

Acknowledgements: This work has been supported by grants SAF2007-61528 and SAF2009-08136 from Ministerio de Ciencia e Innovación of Spain to GH and by grants PI07-1073, RTA RD06/015, PNSD from the Spanish Ministerio de Sanidad y Política Social, Fondo de Investigación Sanitaria, Instituto de Salud Carlos III to RM. Esther Gramage is supported by fellowship AP2008-00726 and Noelia Granado by a Juan de la Cierva fellowship from the Spanish Ministerio de Ciencia e Innovación. 


\section{REFERENCES:}

Amet LE, Lauri SE, Hienola A, Croll SD, Lu Y, Levorse JM, Prabhakaran B, Taira T, Rauvala H, Vogt TF (2001), Enhanced hippocampal long-term potentiation in mice lacking heparin-binding growth-associated molecule. Mol Cell Neurosci 17: 1014-1024.

Atianjoh FE, Ladenheim B, Krasnova IN, Cadet JL (2008) Amphetamine causes dopamine depletion and cell death in the mouse olfactory bulb. Eur J Pharmacol 589: 94-7.

Bowyer JF, Frame LT, Clausing P, Nagamoto-Combs K, Osterhout CA, Sterling CR, Tank AW (1998), Long-term effects of amphetamine neurotoxicity on tyrosine hydroxylase mRNA and protein in aged rats. J Pharmacol Exp Ther 286:10741085.

Darmopil S, Muñetón-Gómez VC, de Ceballos ML, Bernson M, Moratalla R (2008), Tyrosine hydroxylase cells appearing in the mouse striatum after dopamine denervation are likely to be projection neurones regulated by L-DOPA. Eur J Neurosci. 27: 580-592.

Darmopil S, Martín AB, De Diego IR, Ares S, Moratalla R (2009), Genetic inactivation of dopamine D1 but not D2 receptors inhibits L-DOPA-induced dyskinesia and histone activation. Biol Psychiatry. 66: 603-613.

Del Olmo N, Gramage E, Alguacil LF, Pérez-Pinera P, Deuel TF, Herradón G (2009), Pleiotrophin inhibits hippocampal long-term potentiation: a role of pleiotrophin in learning and memory. Growth Factors 27: 189-194.

Fukada M, Fujikawa A, Chow JP, Ikematsu S, Sakuma S, Noda M (2006), Protein tyrosine phosphatase receptor type $\mathrm{Z}$ is inactivated by ligand-induced oligomerization. Febs Lett. 580: 4051-4056.

Goñi-Allo B, Puerta E, Ramos M, Lasheras B, de la Torre R, Aguirre N (2008), Minoxidil prevents 3,4-methylenedioxymethamphetamine-induced serotonin depletions: role of mitochondrial ATP-sensitive potassium channels, Akt and ERK. J Neurochem 104: 914-925.

Gramage E, Alguacil LF, Herradon G (2008), Pleiotrophin prevents cocaine-induced toxicity in vitro. Eur J Pharmacol 595: 35-38.

Gramage E, Putelli A, Polanco MJ, González-Martín C, Ezquerra L, Alguacil LF, Pérez-Pinera P, Deuel TF, Herradón G (2010), The neurotrophic factor pleiotrophin modulates amphetamine-seeking behaviour and amphetamineinduced neurotoxic effects: evidence from pleiotrophin knockout mice. Addict Biol, in press. DOI: 10.1111/j.1369-1600.2009.00202.x

Granado N, Escobedo I, O'Shea E, Colado I, Moratalla R (2008a), Early loss of dopaminergic terminals in striosomes after MDMA administration to mice. Synapse 62: 80-84.

Granado N, O'Shea E, Bove J, Vila M, Colado MI, Moratalla R. (2008b), Persistent MDMA-induced dopaminergic neurotoxicity in the striatum and substantia nigra of mice. J Neurochem.107: 1102-1112.

Granado N, Ares-Santos S, O'Shea E, Vicario-Abejón C, Colado MI, Moratalla R. (2010), Selective Vulnerability in Striosomes and in the Nigrostriatal Dopaminergic Pathway After Methamphetamine Administration : Early Loss of TH in Striosomes After Methamphetamine. Neurotox Res. In press. 
Herradon G, Ezquerra L (2009), Blocking Receptor Protein Tyrosine Phosphatasebeta/zeta: A Potential Therapeutic Strategy for Parkinson's Disease. Curr Med Chem 16: 3322-3329

Herradon G, Ezquerra L, Gramage E, Alguacil LF (2009), Targeting the pleiotrophin/receptor protein tyrosine phosphatase beta/zeta signaling pathway to limit neurotoxicity induced by drug abuse. Mini Rev Med Chem 9: 440-447.

Hida H, Jung CG, Wu CZ, Kim HJ, Kodama Y, Masuda T, Nishino H (2003), Pleiotrophin exhibits a trophic effect on survival of dopaminergic neurons in vitro. Eur J Neurosci 17: 2127-2134.

Hida H, Masuda T, Sato T, Kim TS, Misumi S, Nishino H (2007), Pleiotrophin promotes functional recovery after neural transplantation in rats. Neuroreport 18: 179-183.

Hirata H, Cadet JL (1997), Methamphetamine-induced serotonin neurotoxicity is attenuated in p53-knockout mice. Brain Res. 768: 345-348

Jackson-Lewis V., Vila M., Djaldetti R., Guegan C., Liberatore G., Liu J., O'Malley K. L., Burke R. E. and Przedborski S. (2000), Developmental cell death in dopaminergic neurons of the substantia nigra of mice. J Comp Neurol. 424: 476488.

Jia J, Chen X, Zhu W, Luo Y, Hua Z, Xu Y (2008), CART protects brain from damage through ERK activation in ischemic stroke. Neuropeptides 42: 653-661.

Jung CG, Hida H, Nakahira K, Ikenaka K, Kim HJ, Nishino H (2004), Pleiotrophin mRNA is highly expressed in neural stem (progenitor) cells of mouse ventral mesencephalon and the product promotes production of dopaminergic neurons from embryonic stem cell-derived nestin-positive cells. Faseb J 18: 1237-1239.

Krasnova IN, Ladenheim B, Jayanthi S, Oyler J, Moran TH, Huestis MA, Cadet JL (2001), Amphetamine-induced toxicity in dopamine terminals in CD-1 and C57BL/6J mice: complex roles for oxygen-based species and temperature regulation. Neuroscience 107: 265-74.

Krasnova IN, McCoy MT, Ladenheim B, Cadet JL (2002) cDNA array analysis of gene expression profiles in the striata of wild-type and $\mathrm{Cu} / \mathrm{Zn}$ superoxide dismutase transgenic mice treated with neurotoxic doses of amphetamine. FASEB J 16: 1379-88.

Krasnova IN, Ladenheim B, Cadet JL (2005), Amphetamine induces apoptosis of medium spiny striatal projection neurons via the mitochondria-dependent pathway. Faseb J 19: 851-853.

Le Greves P (2005), Pleiotrophin gene transcription in the rat nucleus accumbens is stimulated by an acute dose of amphetamine. Brain Res Bull 65: 529-532.

Li YS, Milner PG, Chauhan AK, Watson MA, Hoffman RM, Kodner CM, Milbrandt J, Deuel TF (1990), Cloning and expression of a developmentally regulated protein that induces mitogenic and neurite outgrowth activity. Science 250: 1690-1694.

Lovatt M, Filby A, Parravicini V, Werlen G, Palmer E, Zamoyska R (2006), Lck regulates the threshold of activation in primary $\mathrm{T}$ cells, while both Lck and Fyn contribute to the magnitude of the extracellular signal-related kinase response. Mol Cell Biol 26: 8655-8665.

Marchionini DM, Lehrmann E, Chu Y, He B, Sortwell CE, Becker KG, Freed WJ, Kordower JH, Collier TJ (2007), Role of heparin binding growth factors in nigrostriatal dopamine system development and Parkinson's disease. Brain Res 1147: 77-88.

Martin AB, Fernandez-Espejo E, Ferrer B, Gorriti MA, Bilbao A, Navarro M, Rodriguez de F, Moratalla R. (2008), Expression and Function of CB(1) 
Receptor in the Rat Striatum: Localization and Effects on $D(1)$ and $D(2)$ Dopamine Receptor-Mediated Motor Behaviors. Neuropsychopharmacology 33: 1667-1679.

Meng K, Rodriguez-Pena A, Dimitrov T, Chen W, Yamin M, Noda M, Deuel TF (2000), Pleiotrophin signals increased tyrosine phosphorylation of beta betacatenin through inactivation of the intrinsic catalytic activity of the receptor-type protein tyrosine phosphatase beta/zeta. Proc Natl Acad Sci U S A 97: 26032608.

Milner PG, Li YS, Hoffman RM, Kodner CM, Siegel NR, Deuel TF (1989), A novel 17 $\mathrm{kD}$ heparin-binding growth factor (HBGF-8) in bovine uterus: purification and N-terminal amino acid sequence. Biochem Biophys Res Commun 165: 10961103.

Pariser H, Ezquerra L, Herradon G, Perez-Pinera P, Deuel TF (2005), Fyn is a downstream target of the pleiotrophin/receptor protein tyrosine phosphatase beta/zeta-signaling pathway: regulation of tyrosine phosphorylation of Fyn by pleiotrophin. Biochem Biophys Res Commun 332: 664-669.

Pavon N, Martin AB, Mendialdua A, Moratalla R. (2006), ERK phosphorylation and FosB expression are associated with L-DOPA-induced dyskinesia in hemiparkinsonian mice. Biol. Psychiatry 59: 64-74.

Pu C, Vorhees CV (1995), Protective effects of MK-801 on methamphetamine-induced depletion of dopaminergic and serotonergic terminals and striatal astrocytic response: an immunohistochemical study. Synapse 19: 97-104.

Rauvala H (1989), An 18-kd heparin-binding protein of developing brain that is distinct from fibroblast growth factors. Embo J 8: 2933-2941.

Rodrigues TB, Granado N, Ortiz O, Cerdán S, Moratalla R (2007), Metabolic interactions between glutamatergic and dopaminergic neurotransmitter systems are mediated through D(1) dopamine receptors. J Neurosci Res. 85: 3284-3293.

Sabri M, Kawashima A, Ai J, Macdonald RL (2008), Neuronal and astrocytic apoptosis after subarachnoid hemorrhage: A possible cause for poor prognosis. Brain Res. 1238: 163-171.

Sonsalla PK, Jochnowitz ND, Zeevalk GD, Oostveen JA, Hall ED. (1996), Treatment of mice with methamphetamine produces cell loss in the substantia nigra. Brain Res. 738: 172-175.

Taravini IR, Ferrario JE, Delbe J, Ginestet L, Debeir T, Courty J, Murer MG, Gershanik OS, Raisman-Vozari R (2005), Immunodetection of heparin-binding growth associated molecule (pleiotrophin) in striatal interneurons. Brain Res 1066: 196200.

Yamamoto BK, Bankson MG (2005), Amphetamine neurotoxicity: cause and consequence of oxidative stress. Crit Rev Neurobiol 17: 87-117. 
TABLE

\begin{tabular}{|c|c|c|c|c|}
\cline { 2 - 5 } \multicolumn{1}{c|}{} & \multicolumn{2}{c|}{ WT +/+ } & \multicolumn{2}{c|}{ PTN -/- } \\
\hline $\begin{array}{c}\text { Amphetamine } \\
\text { administration }\end{array}$ & Saline & Amphetamine & Saline & Amphetamine \\
\hline Basal & $36.2 \pm 0.1$ & $36.2 \pm 0.2$ & $36.0 \pm 0.1$ & $36.1 \pm 0.1$ \\
\hline $\mathbf{1}^{\text {st }}$ & $36.5 \pm 0.1$ & $37.8 \pm 0.2$ & $36.2 \pm 0.2$ & $37.7 \pm 0.4$ \\
\hline $2^{\text {nd }}$ & $36.7 \pm 0.3$ & $36.8 \pm 0.2$ & $36.6 \pm 0.2$ & $37.8 \pm 0.3 * *$ \\
\hline $\mathbf{3}^{\text {rd }}$ & $35.9 \pm 0.2$ & $37.2 \pm 0.1$ & $36.1 \pm 0.2$ & $38.0 \pm 0.2$ \\
\hline $4^{\text {th }}$ & $35.9 \pm 0.5$ & $36.7 \pm 0.3$ & $36.0 \pm 0.2$ & $37.0 \pm 0.3$ \\
\hline
\end{tabular}

Table 1. Core body temperature recordings in $\mathrm{PTN}-/-$ and $\mathrm{WT}+/+$ mice in basal conditions and after each saline or amphetamine $(10 \mathrm{mg} / \mathrm{kg})$ administration. Results are represented as Mean $\left({ }^{\circ} \mathrm{C}\right) \pm$ S.E.M. **, $\mathrm{P}<0.01$ vs. $\mathrm{WT}+/+\mathrm{Amph}$. 


\section{FIGURE LEGENDS}

Fig. 1. TH expression in striatum of PTN-/- and WT+/+ mice after amphetamine administration. Photomicrographs ilustrate that PTN inactivation increases amphetamine-induced dopaminergic damage. TH-immunostained striatal sections of mice, 4 days after saline (Sal)- or amphetamine (Amph) treatment. Graph represents the proportional stained area of TH-ir in the striatum, data show mean \pm SEM $(n=5$ animals per group). $* * \mathrm{p}<0.01$ vs. Sal. $* * * \mathrm{p}<0.001$ vs. Sal. $\# \mathrm{p}<0.05$ vs. WT+/+. Scale bar $=500 \mu \mathrm{m}$.

Fig. 2. DAT expression after amphetamine administration in striatum of PTN-/and WT+/+ mice. Western blot assays using a DAT antiserum of striatal proteins extracts prepared 4 days after amphetamine $(\mathrm{Amph})$ or saline $(\mathrm{Sal})$ treatment $(\mathrm{n}=5-6$ per experimental group). Anti-DAT antiserum revealed a specific band at 70-75 kDa. Loading control shown in the bottom panel was reacted with $\beta$-actin antiserum. Optical density (OD) measurements revealed a significant decrease of DAT contents in samples from amphetamine-treated PTN-/- mice compared with saline-treated mice. $*$ P $<0.05$ vs. Sal.

Fig. 3. Amphetamine induces loss of TH+ neurons in the substantia nigra of PTN-/mice. Photomicrographs of substantia nigra of $\mathrm{TH}$-immunostained sections from mice sacrified 4 days after saline (Sal) or amphetamine (Amph) treatment. Histograms show the number of $\mathrm{TH}+$ cells in the substantia nigra pars compacta counted by stereology. Inactivation of PTN induced a significant $20 \%$ decrease in $\mathrm{TH}$-ir cells after amphetamine treatment. Data are represented as means \pm SEM $(n=5$ animals per group). $* \mathrm{p}<0.05$ vs. WT $+/+$. Scale bar $=250 \mu \mathrm{m}$.

Fig. 4. Inactivation of PTN potentiates the increase in GFAP staining in SN induced by amphetamine. Photomicrographs of $\mathrm{SN}$ sections from mice 4 days after treatment with saline (Sal) or amphetamine (Amph) stained for GFAP. PTN inactivation increases amphetamine-induced GFAP expression in the substantia nigra from PTN-/mice treated with amphetamine compared to saline-treated mice. $* \mathrm{P}<0.05$ vs. Sal. Scale bar $=50 \mu \mathrm{m}$. 
Fig. 5. Decreased levels of phosphorylation of ERK1/2 in the striatum of PTN-/mice after amphetamine administration. The levels of phosphorylation of ERK1/2 in saline (S, Sal)- and amphetamine (A, Amph)-treated PTN-/- and WT+/+ mice ( $\mathrm{n}=4$ 6/group) were determined in Western blots probed with anti-phospho-ERK1/2 antibodies. Total ERK1/2 amounts were determined using anti-ERK1/2 antibodies. Optical density (OD) measurements revealed decreased p-ERK1/2 contents in samples from PTN-/- mice either treated with saline or amphetamine. ** $\mathrm{p}<0.01$ vs. WT+/+; * $\mathrm{p}<0.05$ vs. WT+/+. 